\title{
Molecular epidemiology of domestic and sylvatic Trypanosoma cruzi infection in rural northwestern Argentina
}

\author{
Marta V. Cardinal ${ }^{\mathrm{a}}$, Marta A. Lauricella ${ }^{\mathrm{b}}$, Leonardo A. Ceballos ${ }^{\mathrm{a}}$, Leonardo Lanatia ${ }^{\mathrm{a}}$, Paula L. \\ Marcet $^{\mathrm{a}}$, Mariano J. Levinc ${ }^{\mathrm{c}}$, Uriel Kitron ${ }^{\mathrm{d}}$, Ricardo E. Gürtler ${ }^{\mathrm{a}}$, and Alejandro G. Schijman ${ }^{\mathrm{c},{ }^{*}}$ \\ aLaboratorio de Eco-Epidemiología, Departamento de Ecología, Genética y Evolución, \\ Universidad de Buenos Aires, Buenos Aires, Argentina \\ bInstituto Nacional de Parasitología "Dr. Mario Fatala Chabén”-ANLIS, Buenos Aires, Argentina \\ 'Laboratorio de Biología Molecular de la Enfermedad de Chagas; Instituto de Investigaciones en \\ Ingeniería Genética y Biología Molecular (INGEBI-CONICET), Buenos Aires, Argentina
}

${ }^{\mathrm{d} D e p a r t m e n t ~ o f ~ E n v i r o n m e n t a l ~ S t u d i e s, ~ E m o r y ~ U n i v e r s i t y, ~ A t l a n t a, ~ U . S . A . ~}$

\section{Abstract}

Genetic diversity of Trypanosoma cruzi populations and parasite transmission dynamics have been well documented throughout the Americas, but few studies have been conducted in the Gran Chaco ecoregion, one of the most highly endemic areas for Chagas disease, caused by T. cruzi. In this study we assessed the distribution of $T$. cruzi lineages (identified by PCR strategies) in Triatoma infestans, domestic dogs, cats, humans and sylvatic mammals from two neighboring rural areas with different histories of transmission and vector control in northern Argentina. Lineage II predominated among the 99 isolates characterized and lineage I among the six isolates obtained from sylvatic mammals. Trypanosoma cruzi lineage IIe predominated in domestic habitats; it was found in $87 \%$ of 54 isolates from Tr. infestans, in $82 \%$ of 33 isolates from dogs, and in the four cats found infected. Domestic and sylvatic cycles overlapped in the study area in the late 1980s, when intense domestic transmission occurred, and still overlap marginally. The introduction of $T$. cruzi from sylvatic into domestic habitats is likely to occur very rarely in the current epidemiological context. The household distribution of $T$. cruzi lineages showed that $T r$. infestans, dogs and cats from a given house compound shared the same parasite lineage in most cases. Based on molecular evidence, this result lends further support to the importance of dogs and cats as domestic reservoir hosts of T. cruzi. We believe that in Argentina, this is the first time that lineage IIc has been isolated from naturally-infected domestic dogs and Tr. infestans.

\section{Keywords}

Chagas disease; Lineage; Trypanosoma cruzi; Triatoma infestans; Dogs; Cats; Surveillance; Vector control

\footnotetext{
(C) 2008 Australian Society for Parasitology. Published by Elsevier Ltd. All rights reserved "Corresponding author Tel.: +54 11-47832871; fax: +54 11-47868576. schijman@dna.uba.ar.
}

Publisher's Disclaimer: This is a PDF file of an unedited manuscript that has been accepted for publication. As a service to our customers we are providing this early version of the manuscript. The manuscript will undergo copyediting, typesetting, and review of the resulting proof before it is published in its final citable form. Please note that during the production process errors may be discovered which could affect the content, and all legal disclaimers that apply to the journal pertain. 


\section{Introduction}

Trypanosoma cruzi has been classified in six discrete genetic subdivisions or lineages, designated as T. cruzi I (TC I), T. cruzi IIa (TC IIa), T. cruzi IIb (TC IIb), T. cruzi IIc (TC IIc), T. cruzi IId (TC IId) and T. cruzi IIe (TC IIe) (Tibayrenc, 2003; Brisse et al., 2001). These lineages appear to be distributed differentially among triatomine bugs, vertebrate host species and habitats in different geographical areas (Higo et al., 2004, Yeo et al., 2005). Although all $T$. cruzi lineages cause human disease, some studies suggest that $T$. cruzi IIb, IId and IIe are more likely to be associated with anthropic environments and chronic Chagas disease patients, $T$. cruzi IIa and IIc to sylvatic environments, and $T$. cruzi I to both (Telleria et al., 2006; Yeo et al., 2005). Although there is a wealth of studies on the genetic diversity of $T$. cruzi populations, there has been a tendency to re-examine the available parasite isolates. Therefore, there is a need for detailed studies of isolates at a single locality scale to better understand the genetic diversity and transmission dynamics of $T$. cruzi (Miles et al., 2003).

Both domestic and sylvatic transmission cycles of T. cruzi occur in the Gran Chaco, a hyperendemic region for Chagas disease extending over Argentina, Bolivia and Paraguay (Gürtler, 2007). Natural infection by $T$. cruzi has been found in several local species of sylvatic mammals (Carcavallo and Martínez, 1968; Ceballos et al., 2006; Diosque et al., 2003; Yeo et al., 2005), whereas the putative sylvatic vectors have only been identified in Bolivia (Noireau et al., 2000). In the Gran Chaco, the bug Triatoma infestans is the main or single domiciliary vector; dogs, humans and chickens are usually the main blood meal sources of domestic bugs, and dogs and cats are considered the most important domestic reservoir hosts of T. cruzi (Minter, 1976; Gürtler et al., 1997, 2007a, b).

The identification of lineages, natural isolates and strains of $T$. cruzi has been conducted using a plethora of biochemical and molecular markers (Macedo et al., 2004). In Argentina, very few studies have attempted to type the local $T$. cruzi strains, and parasites have been characterized mainly by multilocus enzyme electrophoresis (MLEE) (Montamat et al., 1987; 1992; 1996; De Luca d'Oro et al., 1993; Diosque et al., 2003). Parasite zymodemes reported by De Luca d'Oro et al. (1993) were later analyzed by Barnabé et al. (2000) and reinterpreted as belonging to TC I, TC IIb and TC IId. Overall, T. cruzi II (TC II) was more prevalent in the domestic environment, and sylvatic mammals were found infected with both TC I and TC II (De Luca d'Oro et al., 1993). TC IIe was first reported in Argentina by Diosque et al. (2003) and TC IIc by Ceballos et al. (2006).

As part of a longitudinal study aimed at modeling the transmission dynamics and control of T. cruzi in a well-defined rural area of northwestern Argentina, we have described the prevalence of $T$. cruzi infection in two neighboring areas with different histories of vector control and transmission intensity (Cardinal et al., 2006, 2007; Gürtler et al. 2007b). In this study, we have assessed the occurrence and distribution of parasite lineages in domestic and sylvatic hosts and vectors to establish whether domestic and sylvatic cycles of transmission overlap or exist independently in these areas. We also examined the distribution of $T$. cruzi lineages among bugs, dogs and cats at a household level. Based on previous evidence (Cardinal et al., 2006, 2007; Gürtler et al., 2005, 2007a, b), we hypothesized that domestic Tr. infestans and reservoir hosts from the same house compound would share the same parasite lineages. 


\section{Materials and methods}

\subsection{Study area}

Field studies were carried out in several villages centered in Amamá $\left(27^{\circ} 12^{\prime} 33^{\prime}\right.$ 'S, $\left.63^{\circ} 02^{\prime} 10^{\prime \prime} \mathrm{W}\right)$, Province of Santiago del Estero, Argentina. The study area has been described elsewhere (Ceballos et al., 2006; Gürtler et al., 2007b). Briefly, two areas were visited: i) the core area, including Amamá and four neighboring villages (137 houses), and ii) the periphery, including 186 houses grouped in 35 villages or settlements surrounding the core area. The core area has been under sustained, community-based surveillance supervised jointly by the University of Buenos Aires (UBA) research team and the National Vector Control Program (NVCP) since 1992. The peripheral area, operating under the guidelines of the "Plan Ramón Carrillo" program between 1993 and 1999 and variations of it thereafter, experienced pulsed (mostly in 1993-1996 and in 2000-2001), non-supervised, communitybased insecticide applications promoted by NVCP (Cardinal et al., 2006, 2007). The infestation and history of control of Tr. infestans varied widely between villages. All houses were sprayed with pyrethroid insecticides by NVCP personnel in April 2004.

\subsection{Triatomine collections}

Specimens were collected by timed manual collections, light-trapping and householders' collections in different surveys from 2000 to 2006. Timed manual collections consisted of searching for triatomine bugs in all bedrooms (one person) and peridomestic areas (two persons) of all compounds using $0.2 \%$ tetramethrin (Icona, Buenos Aires, Argentina) for 30 min per compound (Gürtler et al., 2007b). Peridomestic structures included corrals for goats or sheep, cows or horses and pigs, chicken coops, trees where chickens roosted, storerooms, kitchens and other possible refuges for triatomines within the area of human activity. Timed manual collections were performed in the core area in March and October 2000; in the core and peripheral areas in October 2002, and during semi-annual monitoring surveys of both areas (323 houses) after community-wide insecticide spraying in 2004. Light-trapping collections were performed in March (late summer), July (winter) and November (spring) 2003, and in March 2004 (Vazquez-Prokopec et al., 2006); additional Tr. infestans were collected from the peridomestic sites that surrounded the light-trap stations during those surveys. Householders were encouraged to collect invading triatomines and were given plastic bags to keep bugs until our next visit.

All bugs were later identified to species and stage at the field laboratory and counted, as described elsewhere (Cardinal et al., 2006). All live or moribund third to fifth instars and adults of $T r$. infestans were individually examined for $T$. cruzi infection within 10 days of capture; Triatoma guasayana and Triatoma garciabesi bugs were examined separately in pools of three insects from the same site. For examination, fecal drops were obtained by abdominal compression and bug feces were diluted with saline solution and microscopically examined at $220-400 \times$ magnification. Infected bugs were shipped to the Instituto Nacional de Parasitología "Dr. Mario Fatala Chabén" (Buenos Aires, Argentina) for parasite isolation.

\subsection{Domestic animal surveys}

Domestic and sylvatic animal processing was conducted according to the Institutional Animal Care and Use Committee protocol No. 04223 at University of Illinois at UrbanaChampaign. A house-to-house census of all dogs was undertaken in all houses of the core area in May 2000 and again in November 2002; the latter also included cats (Cardinal et al., $2006,2007)$. In the peripheral area, the census of dogs and cats was undertaken in three surveys (November 2002, March and July 2003) totaling 103 houses from 17 villages and two isolated settlements. Seropositive animals were examined by xenodiagnosis to confirm T. cruzi infection and to isolate parasites. Xenodiagnosis was performed using 20-30 
laboratory-reared, third- or fourth-instar nymphs of Tr. infestans per animal (Gürtler et al., 2007a). Bugs were provided by the insectary of the National Vector Control Coordination based in Córdoba, Argentina. Pools of feces from five bugs that fed on a given animal were examined for $T$. cruzi infection at $400 \times$ magnification 30 and 60 days after feeding on the study subject. Bugs from each positive pool were re-examined individually. Infectivity to the vector was defined as the number of $T$. cruzi-positive bugs divided by the total number of bugs fed on a given host and examined for infection at least once, excluding those bugs that did not survive to the first examination, and was calculated for xenodiagnosis-positive animals only.

\subsection{Human parasites}

All processing of samples from humans was conducted according to the Institutional Human Use Committee protocol No. 02171 at University of Illinois at Urbana-Champaign. The study objectives were explained to house residents and all participants signed an informed consent form. Human parasite isolates were obtained by natural xenodiagnosis (in 2006) or by artificial xenodiagnosis (in 2007) of people seropositive for $T$. cruzi who sought medical assistance from a volunteer medical team from Hospital Pirovano, Buenos Aires, Argentina. Artificial xenodiagnosis was performed as described by dos Santos et al. (1995) with two modifications: (i) $15 \mathrm{ml}$ - plastic centrifuge tubes with their ends cut were used for collecting heparinized blood, and the latex membrane was attached to the tubes by means of a rubber o-ring; (ii) a copper tube was coiled around the centrifuge tubes containing the blood to maintain it at $37^{\circ} \mathrm{C}$; hot water running inside the tube was pumped by means of an electric motor. Xenodiagnostic procedures were as described for domestic animals using 40 bugs for each patient. Serological test procedures and results have been reported elsewhere (Gürtler et al., 2007b). The mean age of study patients was 49 years (range, 21-79, $n=9$ ) in 2006 and 44 years (range, 28-62, $n=6$ ) in 2007.

\subsection{Sylvatic mammal parasites}

Sylvatic mammals were captured and examined for infection in several surveys from March 2003 to March 2007 (Ceballos et al., 2006). A total of 586 wild mammals from 17 different species was examined for $T$. cruzi infection by xenodiagnosis using five (for rodents, cavids, marmosets), 10 (for armadillos) or 20 (for skunks, opossums, foxes) laboratory-reared uninfected $T r$. infestans as described above. This study combines previously reported results (Ceballos et al., 2006) and a total of 85 new captures performed in March 2007 with a total effort of 2,252 National trap-nights and 1,062 Sherman trap-nights.

\subsection{Parasite isolation}

Isolation procedures have been described (Lauricella et al., 2005). Feces from xenodiagnosis-positive or naturally infected bugs were cultured in brain-heart-infusion (BHI) nutrient agar-rabbit blood biphasic medium, and were also inoculated into 2-4 Balb-C mice. Mice were euthanized 1 month p.i. and hemocultures performed. Cultures were kept at $28^{\circ} \mathrm{C}, 50 \%$ relative humidity and monitored microscopically for parasite growth bi-monthly for 4 months. When at least $3 \times 10^{5}$ parasites $/ \mathrm{ml}$ were reached, cultures were harvested and cryopreserved. "Isolate" refers to cryopreserved $T$. cruzi parasites cultured from a naturally infected individual.

\subsection{PCR}

DNA was extracted as described by Marcet et al. (2006). Infections with T. cruzi were confirmed by kDNA-PCR amplification of the 330 bp fragment from the minicircle DNA of the kinetoplastid genome using primers and cycling conditions published previously (Schijman et al., 2003, Burgos et al, 2005). PCR tests were carried out under conditions that 
prevented DNA contamination. Each PCR run included 100 femtograms of T. cruzi DNA as a positive control, and sterile distilled water instead of DNA as a negative control. Aliquots of $12 \mu \mathrm{l}$ of PCR products were visualized under u.v. light after electrophoresis in $2.5-4 \%$ agarose gels containing ethidium bromide.

Trypanosoma cruzi lineages were identified in culture samples of each infected animal by PCR strategies targeted to spliced-leader DNA, 18s rDNA, 24s alfa rDNA and A10 genomic markers with the incorporation of Taq platinum polymerase (Invitrogen, USA) as described by Marcet et al. (2006). Due to weak sensitivity of the A10 genomic marker, some isolates could not be clearly identified as either TC IIb or TC IIe; these cases were identified as TC $\mathrm{IIb} / \mathrm{e}$, but for the purpose of analyses we considered these as TC IIe. The current study includes the $T$. cruzi populations typed from naturally infected $T$. infestans and sylvatic mammals reported previously (Ceballos et al., 2006; Marcet et al., 2006) as well as 69 new isolates.

\subsection{Data analysis}

Lineage distribution among study areas, habitats and hosts was evaluated with two-tailed Fisher's exact tests and $\chi^{2}$ tests depending on sample size. In order to avoid cells with low expected frequencies, $T$. cruzi lineages with only one observation were grouped together. Mixed infections including TC I and TC II were grouped together with TC I. To analyze the household distribution of parasite lineages, isolates from domestic dogs, cats, Tr. infestans and humans from the same house compound should be compared. However, given that only two human isolates were obtained, human seropositivity for T. cruzi was used as a surrogate variable to indicate the potential occurrence of a human source of parasites. The relationships between dog infectivity to xenodiagnosis (the binary response variables), parasite lineage and dog age were investigated using maximum likelihood logistic multiple regression analysis in Stata statistical software (Stata 9.0, StataCorp, College Station, Texas). Cluster effects on the probability of infecting bugs (due to subject) were allowed for. The probability used for nominal statistical significance was $5 \%$. The Wald test examined the hypothesis that all regression coefficients are 0 .

\section{Results}

In total 2,243 Tr. infestans, 697 domestic dogs, 109 cats, 586 wild mammals and 612 humans were examined for T. cruzi infection between years 2000 and 2007 (Table 1). Trypanosoma cruzi infection was detected in 94 Tr. infestans, 57 domestic dogs, five cats, five opossums and one skunk. The overall prevalence of $T$. cruzi was $0.8 \%$ among 586 sylvatic mammals examined for infection. In the 2007 survey, only one infected opossum was found; xenodiagnosis-negative sylvatic mammals included 15 Galea musteloides, five Didelphis albiventris, two Tolypeutes matacus, 18 Ctenomys sp., one Pecarí tajacu, six Chaetophractus villosus, two Thylamys pusilla, seven Chaetophractus vellerosus, 11 Sigmodontine mice (eight Graomys griseoflavus, two Calomys musculinus and one Calomys callosus), one Lagostomus maximus, 15 Conepatus chinga and one Lycalopex gymnocercus. In humans, seropositivity to T. cruzi was 5.2\% $(n=346)$ in 2006 and 5.3\% $(n=266)$ in 2007 (Gürtler et al., 2007b). A xenodiagnosis-positive seropositive patient was found in 2006 $(11.1 \%, n=9)$ and another in $2007(16.7 \%, n=6)$.

A total of $110(79 \%)$ isolates was successfully cryopreserved from 140 parasite-positive individuals whose samples were cultured; $T$. cruzi lineages were identified from 99 of these (Table 1). Trypanosoma cruzi isolates were particularly difficult to obtain from seropositive humans, most probably because chronic adult infections have a very low parasitemia, and from dead triatomines (which frequently yielded contaminated cultures). 
Both the core and the peripheral area shared all lineages identified (Table 2). The distribution of lineages between areas was not significantly different $\left(\chi^{2}=0.1\right.$, degrees of freedom $(\mathrm{df})=1, P>0.90)$. TC II was the predominant lineage $(89 \%, n=99)$ followed by TC I (9\%). Two mixed infections with both lineages were found. TC IIe was the most prevalent TC II lineage (Table 2). The two main parasite lineages (TC I and TC II) were significantly associated to main habitat type (Fisher's exact test, $P<0.0001$ ); TC II lineages predominated in domestic or peridomestic habitats $(94 \%, n=93)$ whereas TC I was found in five $(83 \%)$ of six infected hosts in sylvatic habitats. TC II was found in 50 (93\%) Tr. infestans, 31 (94\%) dogs, in all four cats, and in both human isolates. TC I was identified in samples from three Tr. infestans bugs and in one dog, and as a mixed infection with TC II in one Tr. infestans specimen and in one dog (Table 2).

\subsection{Lineage distribution among hosts}

Most of the infected Tr. infestans detected were collected in domiciles $(67 \%, n=54)$; infected bugs were less frequently found in peridomestic kitchens and storerooms $(22 \%)$ or corrals (6\%). Three infected adult $T r$. infestans caught by light-traps near a peridomestic goat corral were TC IIe. In domestic or peridomestic Tr. infestans, TC IIe predominated $(67 \%)$ over TC IIb/e (20\%) and TC I (6\%) (Table 2). TC IIe was significantly overrepresented among isolates from bugs $\left(\chi^{2}=70.1, \mathrm{df}=2, P<0.0001\right)$. TC IIc, TC IId and a mixed infection of TC I and TC IIb/e were found in one bug each. The distribution of $T$. cruzi lineages departed significantly from randomness in dogs $\left(\chi^{2}=39.5, \mathrm{df}=2, P<\right.$ 0.0001). Among the 33 isolates from dogs, TC IIe was the most prevalent (82\%), followed by TC IIc (9\%) (Table 2). TC I and TC IIb/e were found in one isolate each (3\%), and in one dog TC I co-occurred with TC IIe. Two dogs that were examined twice (in 2000 and 2002) presented the same isolate TC IIe on both occasions. All four cats were infected with TC IIe and the two human isolates were TC IId (Table 2).

TC IIc was found in three dogs and one Tr. infestans (5\% of the domestic isolates) (Table 2). Fig. 1 illustrates the band pattern of the PCR products yielded by these isolates in agarose gel electrophoresis after ethidium bromide staining. Both the absence of amplification of the 300 or $350 \mathrm{bp}$ fragment of the intergenic region of the mini-exon genes reported by Brisse et al. (2001) as well as the amplification of a $250 \mathrm{bp}$ band reported by Yeo et el. (2005) were observed.

To assess the occurrence of variation in the distribution of $T$. cruzi lineages among hosts within the same region we compared our results (2000-2007) with data collected in Santiago del Estero Province in the late 1980s (De Luca D'Oro et al. 1993) and in Chaco Province over 1999-2001 (Diosque et al. 2003) (Table 3). Given the low numbers of humans and opossums sampled and the homogeneity of results, for these host species we pooled our data with the Chaco data and compared these with data published by De Luca D'Oro et al. (1993). Statistically significant differences were found for humans (Fisher's exact test, $P=$ $0.046)$ but not for opossums $(P=0.26)$. In the comparison between more recent data from Santiago del Estero and Chaco, the distribution of T. cruzi lineages differed significantly between both studies in Tr. infestans (TC I, TC IId and TC IIe, $\chi^{2}=22.7$, df $=2, P<0.0001$ ) but not in dogs (TC IIe vs all other lineages, $P=1.0$ ).

\subsection{Household distribution of T. cruzi lineages}

In order to analyze the household distribution of $T$. cruzi lineages, we focused on 11 houses (marked with an "a" in Table 4) where parasite lineages were identified from bugs and from at least one dog or cat. In nine (82\%) of these houses, 35 of 36 vectors and all 21 dogs or cats with parasites isolated had the same lineage (TC IIe). In house 1, TC IIe was identified in six domestic Tr. infestans and in the only dog infected with T. cruzi (of 10 dogs examined 
for infection) as well as in the three flight-dispersing adult Tr. infestans caught by light-traps in the respective peridomicile (Table 4).

In the core area under sustained surveillance, TC IIc was only found in a 10-year-old dog which had been found seropositive for $T$. cruzi before the massive insecticide spraying campaign in 1992. In the area under pulsed control actions, TC IIc was found in an adult $T r$. infestans collected in a storeroom where chickens roosted (in a house with no domestic dogs or cats), and in two dogs aged 5 and 7 years living in houses 19 and 20 at the same village which had been born to the same female dog (dead at the time of the surveys) (Table 4).

In the area under sustained surveillance, TC I was identified in two peridomestic adult $T r$. infestans (of 97 bugs examined for infection) collected from houses 8 and 9 where no potential domestic source of TC I was identified among 14 dogs or cats examined for infection; only three seropositive adult people (of 17 examined for antibodies) resided permanently in those (Table 4). TC I was also identified (mixed with TC IIe) in a dog aged 12 years which had been found seropositive to $T$. cruzi before the 1992 campaign (Table 4). In the area under pulsed control action, TC I was found in two adult Tr. infestans captured inside domiciles of houses 17 and 14, and in a two-year-old dog living in a house (house 22) which had no bugs in April 2004 (Table 4). At house 17, one TC IIe-infected dog was found in 2003 and one bug infected with TC IIe was collected 1 year later. At house 14, one female $T r$. infestans was found with a mixed infection of TC I and TC IIb/e (probably TC IIe) whereas no putative domestic source of TC I was found among four TC IIe-infected dogs or cats.

\subsection{Infectivity to the vector}

The infectivity to bugs of two xenodiagnosis-positive, seropositive humans was $6.7 \%$ in $2006(n=30$ bugs examined) and 2.5\% $(n=40)$ in 2007, respectively, and did not differ significantly between surveys (Fisher's exact test, $P>0.5$ ) despite different types of xenodiagnosis having been applied. A higher infectivity to bugs was found in cats $(50.0 \%, n$ $=38$ bugs examined $)$ and dogs $(54.4 \%, n=612)$. The infectivity to bugs of infectious seropositive dogs examined by xenodiagnosis was not significantly associated with parasite lineage nor the age of dog (Wald $\chi^{2}=2.6, \mathrm{df}=3$, number of observations $=533, P>0.5$ ).

\section{Discussion}

We believe this is the first study in which a sizable number of parasite isolates obtained from vectors and different host species in the same households have been characterized using molecular methods. The household distribution of $T$. cruzi lineages showed that bugs, dogs and cats from a given house compound shared the same parasite lineage in most cases. Based on molecular evidence, this result lends further support to the importance of dogs and cats as domestic reservoir hosts of T. cruzi given their high infectivity and frequent contact with domestic bugs (Cardinal et al., 2007; Gürtler et al., 2007a, b). Households harboring infected dogs or cats were observed and predicted to be at greater risk of transmission (Cohen and Gürtler, 2001; Gürtler et al., 2005), but molecular evidence of the links between bugs and host species at the household level were lacking. In a similar study in Chaco province, different lineages were found infecting dogs and humans (Diosque et al., 2003). This pattern was explained mainly by host selection of lineages (i.e. clonets), but the cooccurrence of parasite lineages at the household level was not assessed. The household is where the domestic transmission of $T$. cruzi by Tr. infestans is most intense (Cohen and Gürtler, 2001). Here we provide molecular evidence showing that human habitations may also be a source of TC IIe-infected bugs dispersing by flight toward peridomestic sites and beyond (Vazquez-Prokopec et al., 2006). This pattern may arise if recombinant strains in humans (i.e. those which might arise from genetic exchange during drug selection in the 
human host) had the enhanced capacity to spread within a household given the close proximity of other members of the family, Tr. infestans and domestic household animals. Further studies combining serological, parasitological and molecular methods at the household scale are essential for a better understanding of parasite transmission dynamics.

The overall distribution of $T$. cruzi lineages among vectors and reservoir hosts was similar in two neighboring rural areas with different histories of vector control and transmission intensity. TC II predominated in domestic habitats and TC I in sylvatic ecotopes. Coinciding with our findings, TC IIe and TC I were the predominant lineages typed by MLEE in domestic and sylvatic habitats, respectively, in a rural endemic area in Chaco Province located some $150 \mathrm{~km}$ north-east from that which we studied (Diosque et al. 2003). Unlike our study, TC IId predominated in bugs from Chaco Province. The predominance of lineage I among isolates from sylvatic habitats is probably due to the role of opossums as the major local sylvatic reservoir host of T. cruzi (Schweigmann et al. 1999) and to the absence of $T$. cruzi infection among armadillos. Opossums have consistently been found infected almost exclusively with lineage I throughout the Chaco region and the Americas (Barnabé et al., 2000; Ceballos et al., 2006; Diosque et al., 2003; Wisnivesky-Colli et al., 1992; Yeo et al., 2005). Armadillos, especially Dasypus novemcinctus, are sylvatic hosts of T. cruzi II in the Paraguayan Chaco (Yeo et al., 2005) but they are very rare in the study area. The absence of T. cruzi infection in other armadillo species examined further explains the observed pattern.

In the core area under sustained vector control, half of the infected dogs had already been found infected before the insecticide spraying campaign conducted in 1992. Therefore, $T$. cruzi isolates from those (TC I, TC IIc and TC IIe) most likely represented parasite strains circulating a decade before. Conversely, parasites from native dogs born after the insecticide spraying campaign, with stable local residence in the core area, represented the strains currently circulating in the area. All five of these dogs were found infected with TC IIe, and four of these were compatible with vertically acquired infections (Cardinal et al., 2006). Coincidentally, TC IIe was also the predominant lineage found in Tr. infestans in the core area.

Previous studies showed that lineage TC IId (or its zymodeme equivalent) predominated among human isolates from Santiago del Estero and Chaco provinces and in a large set of human isolates from Argentina and Bolivia (Brenière et al., 2002; Burgos et al., 2007; Diosque et al., 2003; Montamat et al., 1992). TC IId was also frequently identified in human isolates from Paraguay (Chapman et al., 1984), and was the prevalent lineage detected in peripheral blood samples from congenital Chagas disease patients in Argentina (Burgos et al., 2007). Moreover, TC IId has been found in peripheral blood of patients with Chagas disease and AIDS, whereas other lineages such as TC IIb and TC IIe were found in heart, brain and skin lesions (Burgos et al., 2006, 2007; A.G. Schijman, unpublished data). In our study, the two human isolates identified were typed as TC IId. Given that T. cruzi natural populations display different tissue tropism in mammalian hosts (Macedo et al., 2004; Burgos et al., 2005, 2008) we cannot reject the possibility that TC IIe can also cause human infection and disease despite displaying low degrees of parasitemia as determined by xenodiagnosis.

In this study we found a low percentage of positive xenodiagnosis among seropositive humans, but not among seropositive dogs examined concurrently. Human parasites were obtained in 2006 by natural (direct) xenodiagnosis and in 2007 by artificial xenodiagnosis. Neither the xenodiagnosis-positive rate nor the infectivity to bugs differed significantly between 2006 and 2007 despite different types of xenodiagnosis having been applied. A previous serological and xenodiagnosis survey in the Amamá study area conducted in the early 1990 s with the same procedures used herein showed that only $29.3 \%$ of seropositive 
humans were xenodiagnosis-positive, and their infectivity to bugs was very low ( $\sim 3 \%)$ (Gürtler et al., 1996). In our previous xenodiagnosis survey and in others (e.g. Hoff et al., 1979) conducted in unselected, well-defined human populations, the proportion of seropositive persons with detectable parasitemia declined with age. Therefore, the low xenodiagnosis-positive rate for humans recorded in our study area in recent years could be due to the absence of seropositive children and teenagers (range of patients, 21-79 years old) in the study. The overall xenodiagnosis-positive rate for seropositive humans was $13.3 \%$ (two of 15), which is closer to previous estimates for the same age group (15.2\%) in the early 1990s.

The distribution of $T$. cruzi lineages among vectors and hosts should be interpreted cautiously since many biological characteristics of the strains, such as differential host selection, histotropism and lineage selection during parasite culture, could be affecting the observed patterns. Not working with clones may also have biased our results, since there is evidence that mixed infections with two lineages may only be revealed when clones are genotyped (Montamat et al., 1992, Yeo et al., 2005, 2007) or when parasites are typed directly from fecal samples (Bosseno et al., 1996; Marcet et al., 2006) or from other clinical specimens (Burgos et al., 2007, 2008). Resident host individuals not examined for infection or who had disappeared shortly before the surveys may also have contributed to the observed household distribution of lineages in an unknown way.

Previous studies based on MLEE concluded that domestic and sylvatic transmission cycles of $T$. cruzi overlapped partially throughout Argentina including rural areas within the Chaco region (Wisnivesky-Colli et al., 1992; De Luca d'Oro et al., 1993; Diosque et al., 2003). In the late 1980s, when intense domestic transmission of T. cruzi was prevalent and widespread, sylvatic mammals (opossums, ferrets and skunks) were sometimes found infected with TC IId, which also infected domestic dogs and Tr. infestans in Santiago del Estero (Wisnivesky-Colli et al., 1992; De Luca d'Oro et al., 1993). In such an epidemiological context of intense transmission, the observed distribution of lineages was probably a spillover of parasite strains from domestic into sylvatic habitats. This has also been observed in Brazil (Diotaiuti et al., 1995).

We believe that in Argentina, this is the first time that TC IIc has been isolated from naturally infected domestic dogs and from Tr. infestans. The current finding of predominantly sylvatic-associated lineages (i.e. TC I and TC IIc) in domestic vectors and reservoir hosts from the core and peripheral areas lends further support to the existence of marginal overlap between transmission cycles, though in a different epidemiological context and with much lower transmission. Sylvatic triatomines or mammals invading artificial ecotopes and synanthropic mammals (i.e., rats, mice, domestic dogs and cats) or humans visiting natural foci may introduce sylvatic parasites into the domestic environment (Barreto, 1975; Diotaiuti et al., 1995). Opossums frequently approach human dwellings and may serve as a bridge host between the sylvatic and the domestic environment (Diotaiuti et al., 1995, Schweigmann et al., 1999). However, given the sharp decline in the abundance and prevalence of T. cruzi in opossums in the study area (Ceballos et al., 2006), such introductions seem unlikely at present. If opossums acquired T. cruzi infection from domestic sources, parasite lineages other than TC I would infect opossums as shown in the past (Wisnivesky-Colli et al. 1992; De Luca d'Oro et al. 1993). The remarkable finding of a TC I-infected opossum in 2007, when the domestic and peridomestic abundance of $T r$. infestans was very low or nil and no T. cruzi infection in bugs had been detected since the 2004 insecticide spraying (Gürtler et al., 2007b), further suggests the occurrence of a lowlevel, independent sylvatic transmission cycle in the area. 
The putative sylvatic vector of T. cruzi in Argentina has not been identified (Ceballos et al., 2006), and $T r$. infestans has been the only species found infected with $T$. cruzi in our study area in over a decade (Gürtler et al., 2007b; Marcet et al., 2006; Schijman et al., 2006). However, the recent finding of sylvatic colonies of Tr. infestans (Ceballos et al., unpublished data) and the collection of $T$. cruzi-infected Tr. infestans in light-traps (Vazquez-Prokopec et al., 2006) suggest the possibility of parasite introduction by flying bugs. Infected Tr. infestans dispersing from sylvatic colonies may account for the five adult bugs found infected with TC I or TC IIc in households where no potential domestic source of these lineages was detected. Nevertheless, more human isolates from the study houses are needed to assess their eventual contribution as sources of TC I or TC IIc. Future studies on the blood meals of the bugs may cast some light on the putative sources of infection.

Dogs, cats and rodents could mediate the introduction of sylvatic T. cruzi lineages into the domestic environment. Although cats were frequently reported to stray and hunt in the forest (Cardinal et al., 2006), their current contribution to such introduction appears to be negligible because the few cats that were infected had TC IIe. Moreover, no infection was found among 162 rodents examined for T. cruzi during 2002-2007 (Ceballos et al., 2006; this study) despite rodent infections being common in Bolivia, Chile and Brazil (Cortez et al., 2006, Herrera et al., 2007; Rozas et al., 2007). Dogs could become infected with TC I or TC IIc while visiting the forest or hunting, since dogs were reported to kill opossums in this area (Schweigmann et al., 1999). In the core area, the two dogs infected with TC I or TC IIc had already been found infected before 1992, when intense transmission of T. cruzi occurred and transmission cycles overlapped to some extent. In the peripheral area, the three TC I- or TC IIc-infected dogs were reported to be hunters (suggesting a possible oral route of infection), but this mechanism of transmission is unlikely to occur given the current very low prevalence of $T$. cruzi in sylvatic mammals (0.8\%).

In conclusion, domestic and sylvatic cycles of $T$. cruzi transmission overlapped in our study area in the late 1980s and still overlap in the area, although marginally. The introduction of T. cruzi from sylvatic into domestic habitats would rarely occur in the current epidemiological context. Based on evidence provided by the molecular identification of lineages, the role of domestic dogs as major domestic reservoirs of $T$. cruzi in the Chaco region has been reinforced. For improved control during surveillance, T. cruzi transmission control programs should consider including strategies to prevent infected dog-vector encounters such as insecticide-impregnated collars for infected animals, parasiticidal drug treatment, or targeted insecticide spraying of houses with infected animals.

\section{Acknowledgments}

We are grateful to Margarita Bisio, Tomás Duffy, Juan M. Burgos, Gonzalo M. Vazquez-Prokopec, María C. Cecere, Mónica B. Castañera, María M. Orozco, Francisco G. Petrocco, Virginia Rago, Nathalia Scioscia, Gustavo Enriquez, Pablo Teta, Emiliano Muschetto, Raúl Stariolo and Cristina G. Maidana for field and laboratory assistance. For assistance and data sharing, we thank personnel from Hospital Pirovano (Buenos Aires), who have developed a community health care project in Trinidad and Mercedes since 2002, and C. Piazza, L. Pons, and H. López Alcoba. Reference strains of $T$. cruzi I and $T$. cruzi II were kindly provided by Patricio Diosque and Miguel A. Basombrío (Instituto de Patología Experimental, Universidad Nacional de Salta, Argentina) and by Michel Tibayrenc (UR62 "Genetics of Infectious Diseases", IRD Centre, Montpellier, France). Financial support: This study was supported by awards from the National Institutes of Health/National Science Foundation Ecology of Infectious Disease program award R01 TW05836 funded by the Fogarty International Center and the National Institute of Environmental Health Sciences to U.K. and R.E.G., the Agencia Nacional de Promoción Científica y Técnica (Argentina) to R.E.G and A.G.S. and University of Buenos Aires to R.E.G. M. J. Levin, R. E. Gürtler and A. G. Schijman are members of Consejo Nacional de Investigaciones Científicas y Técnicas Researcher's Career. 


\section{References}

Barnabé C, Brissé S, Tibayrenc M. Population structure and genetic typing of Trypanosoma cruzi, the agent of Chagas disease: a multilocus enzyme electrophoresis approach. Parasitology. 2000; 120:513-526. [PubMed: 10840981]

Barreto, MP. New Approaches in American Trypanosomiasis Research. PAHO/WHO; Washington: 1975. Possible role of wild mammals and triatomines in the transmission of Trypanosoma cruzi to man; p. 307-318.Scientific Publication ${ }^{\circ} 318$

Bosseno MF, Telleria J, Vargas F, Yaksic N, Noireau F, Morin A, Brenière SF. Trypanosoma cruzi: Study of the distribution of two widespread clonal genotypes in Bolivian Triatoma infestans vectors shows a high frequency of mixed infections. Experim. Parasitol. 1996; 83:275-282.

Brenière SF, Bosseno MF, Noireau F, Yacsik N, Liegeard P, Aznar C, Hontebeyrie M. Integrate study of a Bolivian population infected by Trypanosoma cruzi, the agent of Chagas disease. Mem. Inst. Oswaldo Cruz. 2002; 97:289-295. [PubMed: 12048553]

Brisse S, Verhoef J, Tibayrenc M. Characterisation of large and small subunit rRNA and mini-exon genes further supports the distinction of six Trypanosoma cruzi lineages. Int. J. Parasitol. 2001; 31:1218-1226. [PubMed: 11513891]

Burgos JM, Begher SB, Freitas JM, Bisio M, Duffy T, Altcheh J, Teijeiro R, Lopez Alcoba H, Deccarlini F, Freilij H, Levin MJ, Levalle J, Macedo AM, Schijman AG. Molecular diagnosis and typing of Trypanosoma cruzi populations and lineages in cerebral Chagas disease in a patient with AIDS. Am. J. Trop. Med. Hyg. 2005; 73:1016-1018. [PubMed: 16354804]

Burgos JM, Altcheh J, Bisio M, Duffy T, Valadares HM, Seidenstein ME, Piccinali R, Freitas JM, Levin MJ, Macchi L, Macedo AM, Freilij H, Schijman AG. Direct molecular profiling of minicircle signatures and lineages of Trypanosoma cruzi bloodstream populations causing congenital Chagas disease. Int. J. Parasitol. 2007; 37:1319-1327. [PubMed: 17570369]

Burgos JM, Begher S, Valadares Silva H, Bisio M, Duffy T, Levin MJ, Macedo AM, Schijman AG. Case report: Molecular identification of Trypanosoma cruzi I tropism for central nervous system in Chagas reactivation due to AIDS. Am. J. Trop. Med. Hyg. 2008; 78:294-297. [PubMed: 18256432]

Carcavallo RU, Martinez A. Entomoepidemiología de la República Argentina. Investigaciones Científicas de las Fuerzas Armadas Argentinas. 1968; 1:76-92.

Cardinal MV, Castañera MB, Lauricella MA, Cecere MC, Ceballos LA, Vazquez-Prokopec GM, Kitron U, Gürtler RE. A prospective study of the effects of sustained vector surveillance following community-wide insecticide application on Trypanosoma cruzi infection of dogs and cats in rural northwestern Argentina. Am J Trop Med Hyg. 2006; 75:753-761. [PubMed: 17038707]

Cardinal MV, Lauricella MA, Marcet PL, Orozco MM, Kitron U, Gürtler RE. Impact of communitybased vector control on house infestation and Trypanosoma cruzi infection in Triatoma infestans, dogs and cats in the Argentine Chaco. Acta Trop. 2007; 103:201-211. [PubMed: 17686448]

Ceballos LA, Cardinal MV, Vazquez-Prokopec GM, Lauricella MA, Orozco MM, Cortinas R, Schijman AG, Levin MJ, Kitron U, Gürtler RE. Long-term reduction of Trypanosoma cruzi infection in sylvatic mammals following deforestation and sustained vector surveillance in northwestern Argentina. Acta Trop. 2006; 98:286-296. [PubMed: 16839513]

Cohen JE, Gürtler RE. Modeling household transmission of American Trypanosomiasis. Science. 2001; 293:694-698. [PubMed: 11474111]

Chapman MD, Baggaley RC, Godfrey-Fausset PF, Malpas TJ, White G, Canese J, Miles MA. Trypanosoma cruzi from the Paraguayan Chaco: isoenzyme profiles of strains isolated at Makthlawaiya. J Protozool. 1984; 31:482-486. [PubMed: 6239030]

Cortez MR, Pinho AP, Cuervo P, Alfaro F, Solano M, Xavier SC, D'Andrea PS, Fernandes O, Torrico F, Noireau F, Jansen AM. Trypanosoma cruzi (Kinetoplastida Trypanosomatidae): ecology of the transmission cycle in the wild environment of the Andean valley of Cochabamba, Bolivia. Exp Parasitol. 2006; 114:305-313. [PubMed: 16797540]

De Luca d'Oro GM, Cardenal CN, Pret B, Crisci JV, Montamat EE. Genetic structure of Trypanosoma cruzi populations from Argentina estimated from enzyme polymorphism. Parasitology. 1993; 107:405-410. [PubMed: 8278220] 
Diosque P, Barnabé C, Padilla A, Marco J, Cardozo R, Cimino R, Nasserd J, Tibayrenc M, Basombrío M. Multilocus enzyme electrophoresis analysis of Trypanosoma cruzi isolates from a geographically restricted endemic area for Chagas' disease in Argentina. Int. J. Parasitol. 2003; 33:997-1003. [PubMed: 13129520]

Diosque P, Padilla A, Cimino RO, Cardozo RM, Sanchez Negrette O, Marco JD, Zaca R, Meza C, Juarez A, Rojo H, Rey R, Corrales RM, Nasser JR, Basombrío MA. Chagas' disease in rural areas of Chaco province, Argentina: epidemiologic survey in humans, reservoirs, and vectors. Am. J. Trop. Med. Hyg. 2004; 71:590-593. [PubMed: 15569789]

Diotaiuti L, Pereira AS, Loiola CF, Fernandes AJ, Schofield CJ, Dujardin JP, Pinto Dias JC, Chiari E. Inter-relation of sylvatic and domestic transmission of Trypanosoma cruzi in areas with and without domestic vectorial transmission in Minas Gerais, Brazil. Mem. Inst. Oswaldo Cruz. 1995; 90:443-448. [PubMed: 8551947]

dos Santos AH, da Silva IG, Rassi A. A comparative study between natural and artificial xenodiagnosis in chronic Chagas' disease patients. Rev. Soc. Bras. Med. Trop. 1995; 28:367-373. [PubMed: 8668837]

Gürtler RE, Cecere MC, Castañera MB, Canale DN, Lauricella MA, Chuit R, Cohen JE, Segura EL. Probability of infection with Trypanosoma cruzi of the vector Triatoma infestans fed on infected humans and dogs in northwest Argentina. Am. J Trop. Med. Hyg. 1996; 55:24-31.

Gürtler RE, Cohen JE, Cecere MC, Chuit R. Shifting host choices of the vector of Chagas disease Triatoma infestans in relation to the availability of hosts in houses in northwest Argentina. J.Appl. Ecol. 1997; 34:699-715.

Gürtler RE, Cecere MC, Lauricella MA, Petersen RM, Canale D, Castañera MB, Chuit R, Segura EL, Cohen JE. Incidence of Trypanosoma cruzi infection among children following domestic reinfestation after insecticide spraying in rural northwestern Argentina. Am. J. Trop. Med. Hyg. 2005; 73:95-103. [PubMed: 16014842]

Gürtler, RE. Eco-epidemiología regional de la transmisión vectorial: Enfermedad de Chagas en el Gran Chaco. In: Silveira, AC., editor. La enfermedad de Chagas. A la puerta de los 100 años del conocimiento de una endemia americana ancestral. Organización Panamericana de la SaludFundación Mundo Sano; Buenos Aires: 2007. p. 137-155.

Gürtler RE, Cecere MC, Lauricella MA, Cardinal MV, Kitron U, Cohen JE. Domestic dogs and cats as sources of Trypanosoma cruzi infection in rural northwestern Argentina. Parasitology. 2007a; 134:69-82.

Gürtler RE, Kitron U, Cecere MC, Segura EL, Cohen JE. Sustainable vector control and management of Chagas disease in the Gran Chaco, Argentina. Proc. Nat. Acad. Sci. U.S. 2007b; 104:1619416199.

Herrera HM, Rademaker V, Abreu UGP, D'Andrea PS, Jansen AM. Variables that modulate the spatial distribution of Trypanosoma cruzi and Trypanosoma evansi in the Brazilian Pantanal. Acta Trop. 2007; 102:55-62. [PubMed: 17451633]

Higo H, Miura S, Horio M, Mimori T, Hamano S, Agatsuma T, Yanagi T, Cruz-Reyes A, Uyema N, Rojas de Arias A, Matta V, Akahane H, Hirayama K, Takeuchi T, Tada I, Himeno K. Genotypic variation among lineages of Trypanosoma cruzi and its geographic aspects. Parasitol. Int. 2004; 53:337-344. [PubMed: 15464443]

Hoff R, Mott KE, Franca Silva J, Menezes V, Hoff JN, Barret TV, Sherlock I. Prevalence of parasitemia and seroreactivity to Trypanosoma cruzi in a rural population of northeast Brazil. Am J Trop Med Hyg. 1979; 28:461-466. [PubMed: 110161]

Lauricella MA, Stariolo RL, Riarte AR, Segura EL, Gürtler RE. Distribution and pathogenicity of Trypanosoma cruzi isolated from peridomestic populations of Triatoma infestans and Triatoma guasayana from rural western Argentina. Mem. Inst. Oswaldo Cruz. 2005; 100:123-129. [PubMed: 16021298]

Macedo AM, Machado CR, Oliveira RP, Pena SDJ. Trypanosoma cruzi: Genetic structure of populations and relevance of genetic variability to the pathogenesis of Chagas Disease. Mem. Inst. Oswaldo Cruz. 2004; 99:1-12. [PubMed: 15057339]

Marcet PL, Duffy T, Cardinal MV, Lauricella MA, Levin MJ, Kitron U, Gürtler RE, Schijman AG. PCR-based screening and typing of Trypanosoma cruzi lineages directly from faecal samples of triatomine bugs from northwestern Argentina. Parasitology. 2006; 132:1-9. [PubMed: 16393348] 
Miles, MA.; Yeo, M.; Gaunt, M. Genetic diversity of Trypanosoma cruzi and the Epidemiology of Chagas Disease. In: Kelly, JM., editor. Molecular Mechanisms in the Pathogenesis of Chagas Disease. Eurekah.com \& Kluwer Academic/ Plenum Publishers; 2003. p. 1-15.

Minter, DM. Pan American Health Organization, New Approaches in American Trypanosomiasis Research. Washington DC: 1976. Effects on transmission to man of the presence of domestic animals in infested households; p. 330-337.Scientific Publication No. 318

Montamat EE, Arauzo S, Cazzulo JJ, Subias E. Characterization by electrophoretic zymograms of 19 Trypanosoma cruzi clones derived from two chronic chagasic patients. Comp. Biochem. Physiol. 1987; 87:417-422.

Montamat EE, De Luca d'Oro G, Perret B, Rivas C. Characterization of Trypanosoma cruzi from Argentina by electrophoretic zymograms. Acta Trop. 1992; 50:125-133. [PubMed: 1685868]

Montamat EE, De Luca d'Oro GM, Gallerano RH, Sosa R, Blanco A. Characterization of Trypanosoma cruzi populations by zymodemes: correlation with clinical picture. Am. J. Trop. Med. Hyg. 1996; 55:625-628. [PubMed: 9025688]

Noireau F, Flores R, Gutierrez T, Abad-Franch F, Flores E, Vargas F. Natural ecotopes of Triatoma infestans dark morph and other sylvatic triatomines in the Bolivian Chaco. Trans. R. Soc. Trop. Med. Hyg. 2000; 94:23-27. [PubMed: 10748892]

Rozas M, Botto-Mahan C, Coronado X, Ortiz S, Cattan PE, Solari A. Coexistence of Trypanosoma cruzi genotypes in wild and periodomestic mammals in Chile. Am. J. Trop. Med. Hyg. 2007; 77:647-653. [PubMed: 17978065]

Schijman AG, Altcheh J, Burgos JM, Biancardi M, Bisio M, Levin M, Freilij H. Aetiological treatment of Congenital Chagas disease diagnosed and monitored by the polymerase chain reaction. J. Antimicrob. Chemother. 2003; 52:441-449. [PubMed: 12917253]

Schijman AG, Lauricella MA, Marcet PL, Duffy T, Cardinal MV, Bisio M, Levin MJ, Kitron U, Gürtler RE. Differential detection of Blastocrithidia triatomae and Trypanosoma cruzi by amplification of 24salpha ribosomal RNA genes in faeces of sylvatic triatomine species from rural northwestern Argentina. Acta Trop. 2006; 99:50-54. [PubMed: 16887092]

Schweigmann NJ, Pietrokovsky S, Bottazzi V, Conti O, Bujas MA, Wisnivesky-Colli C. Estudio de la prevalencia de infección por Trypanosoma cruzi en zarigüeyas (Didelphis albiventris) en Santiago del Estero, Argentina. Rev. Panam. Salud Pública. 1999; 6:371-377.

Telleria J, Lafay B, Virreira M, Barnabé C, Tibayrenc M, Svoboda M. Trypanosoma cruzi: Sequence analysis of the variable region of kinetoplast minicircles. Exp. Parasitol. 2006; 45:221-229.

Tibayrenc M. Genetic subdivisions within Trypanosoma cruzi (Discrete Typing Units) and their relevance for molecular epidemiology and experimental evolution. Kinetoplastid Biol. Dis. 2003; 2:12. [PubMed: 14613498]

Vazquez-Prokopec GM, Ceballos LA, Marcet PL, Cecere MC, Cardinal MV, Kitron U, Gürtler RE. Seasonal variations in active dipersal of natural populations of Triatoma infestans in rural northwestern Argentina. Med. Vet. Entomol. 2006; 20:273-279. [PubMed: 17044877]

Wisnivesky-Colli C, Schweigmann NJ, Alberti A, Pietrokovsky SM, Conti O, Montoya S, Riarte A, Rivas C. Sylvatic American trypanosomiasis in Argentina. Trypanosoma cruzi infection in mammals from the Chaco forest in Santiago del Estero. Trans. Roy. Soc. Trop. Med. Hyg. 1992; 86:38-41. [PubMed: 1566301]

Yeo M, Acosta M, Llewellyn M, Sánchez H, Adamson S, Miles G, López E, González N, Patterson J, Gaunt M, Rojas de Arias A, Miles MA. Origins of Chagas disease: Didelphis species are natural hosts of Trypanosoma cruzi I and armadillos hosts of Trypanosoma cruzi II, including hybrids. Int. J. Parasitol. 2005; 35:225-233. [PubMed: 15710443]

Yeo M, Lewis MD, Carrasco HJ, Acosta M, Llewellyn M, da Silva Valente SA, de Costa Valente V, Rojas de Arias A, Miles MA. Resolution of multiclonal infections of Trypanosoma cruzi from naturally infected triatomine bugs and from experimentally infected mice by direct plating on a sensitive solid medium. Int. J. Parasitol. 2007; 37:111-120. [PubMed: 17052720] 


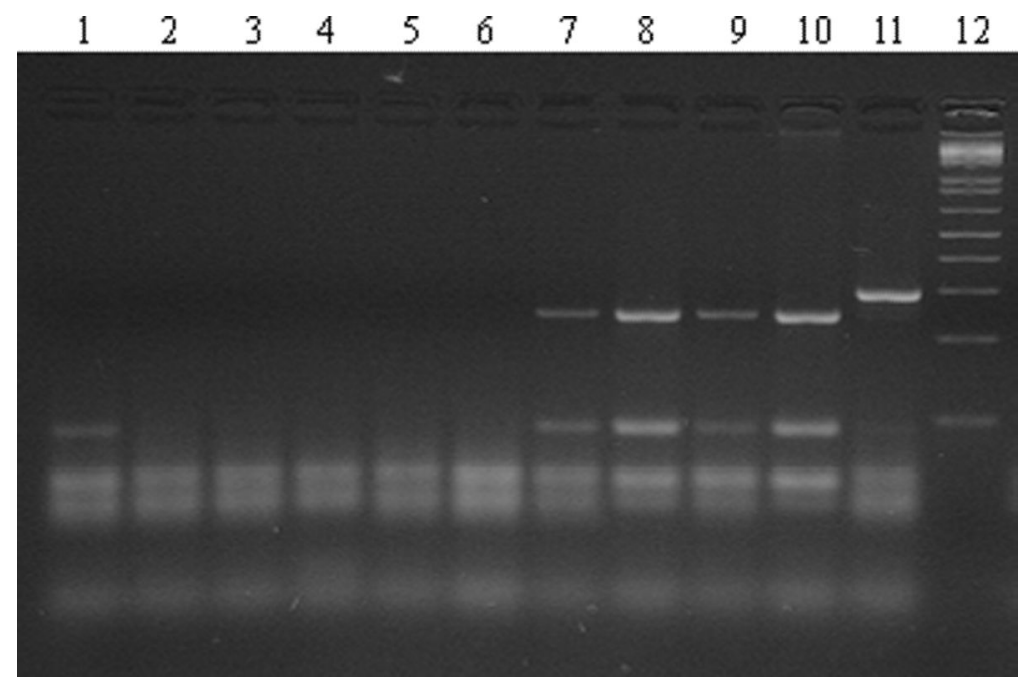

Fig. 1.

Amplification of the intergenic region of the mini-exon genes of Trypanosoma cruzi. with primers TCC and TC 1; lanes (1-3) negative controls: (1) M5631, reference strain of TC IIc; (2) CanIII, reference strain of TC IIa; (3) X-10, reference strain of TC I; lanes (4-5) negative controls; lane (6) domestic dog TC IIc, with no amplification; lanes (7-10) TC IIc, yielding the $250 \mathrm{bp}$ band pattern ; (7) peridomestic Tr. infestans; (8-9) domestic dogs; (10) Conepatus chinga, skunk; (11) CL Brener, reference strain of TC IIe; (12) 100 bp ladder. 


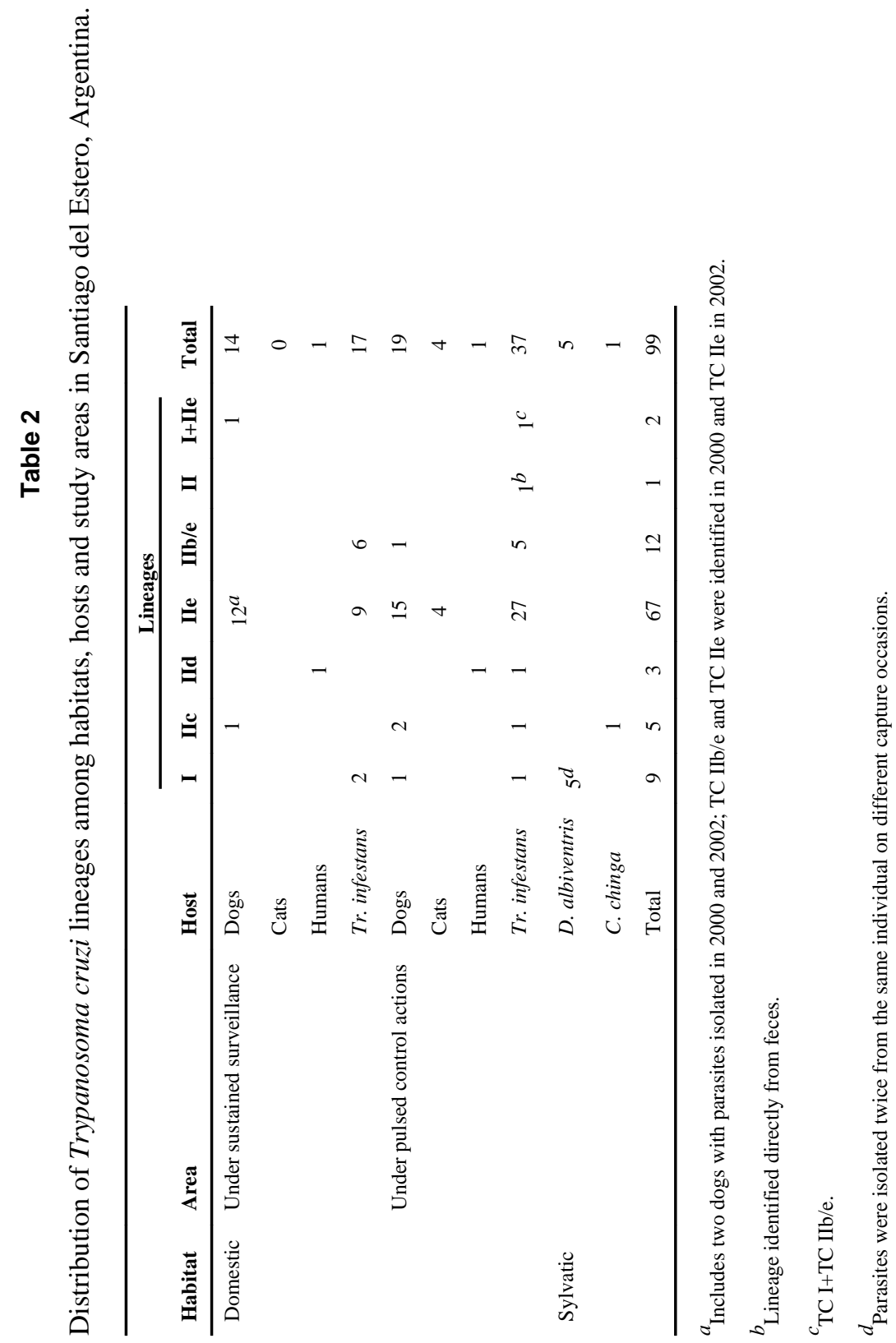



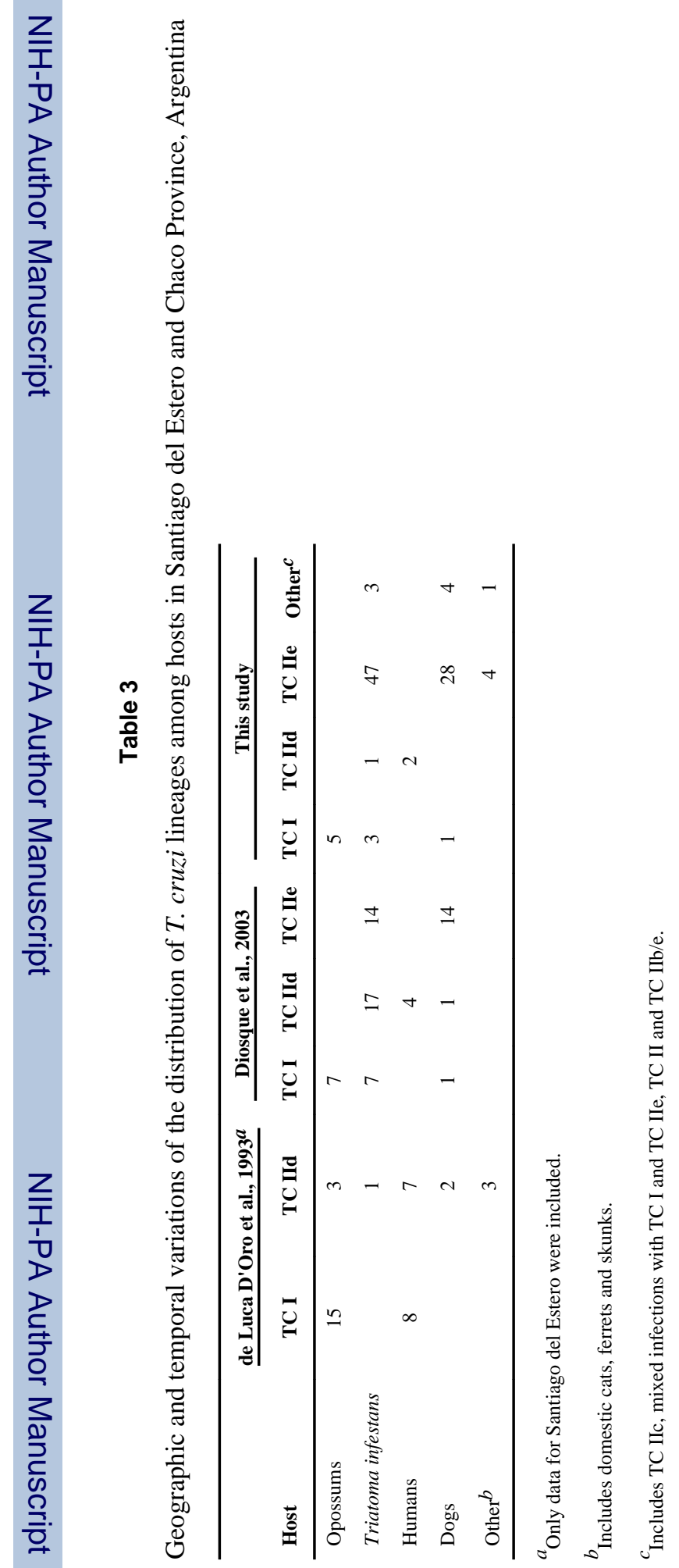

Int J Parasitol. Author manuscript; available in PMC 2011 July 26. 


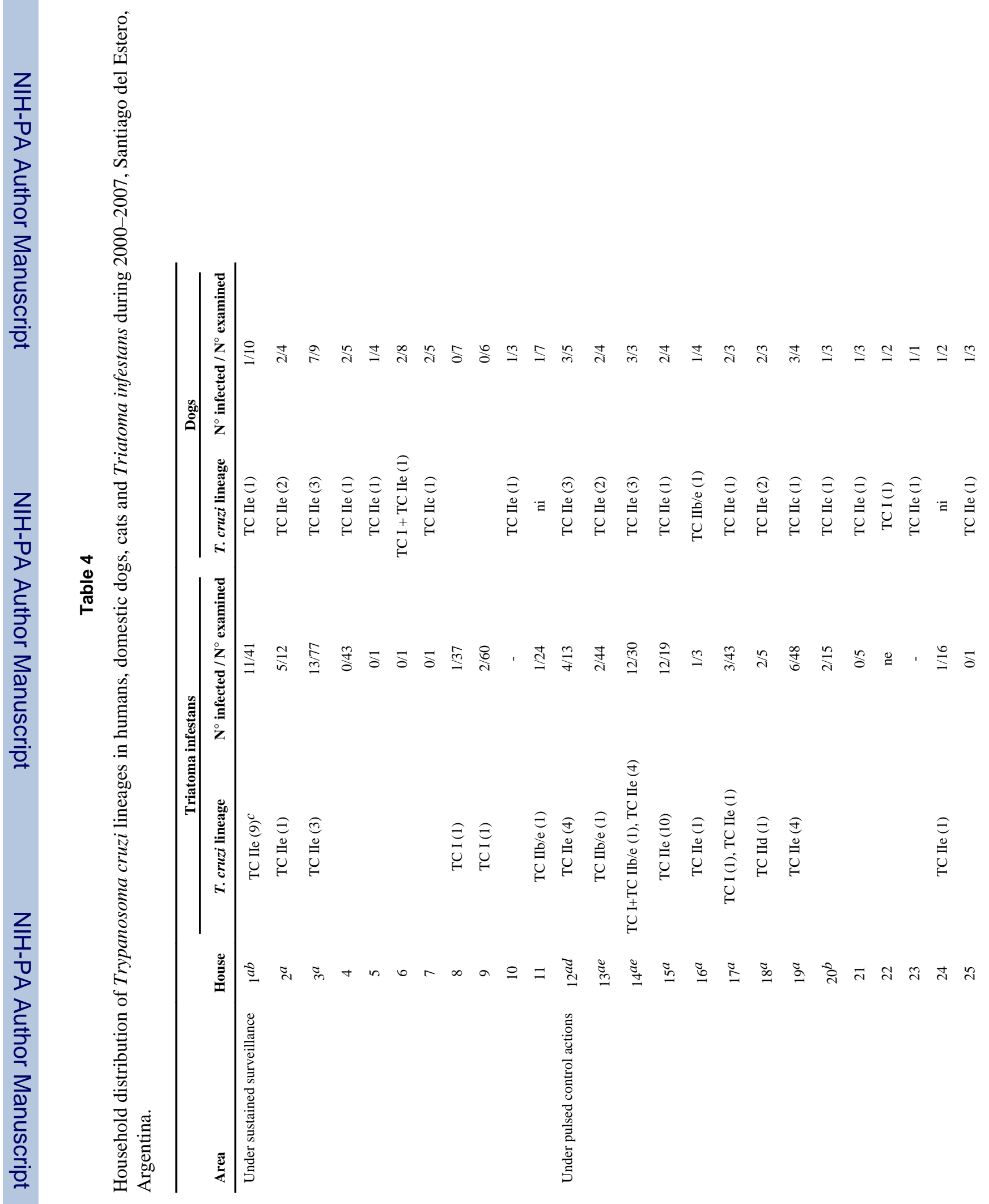




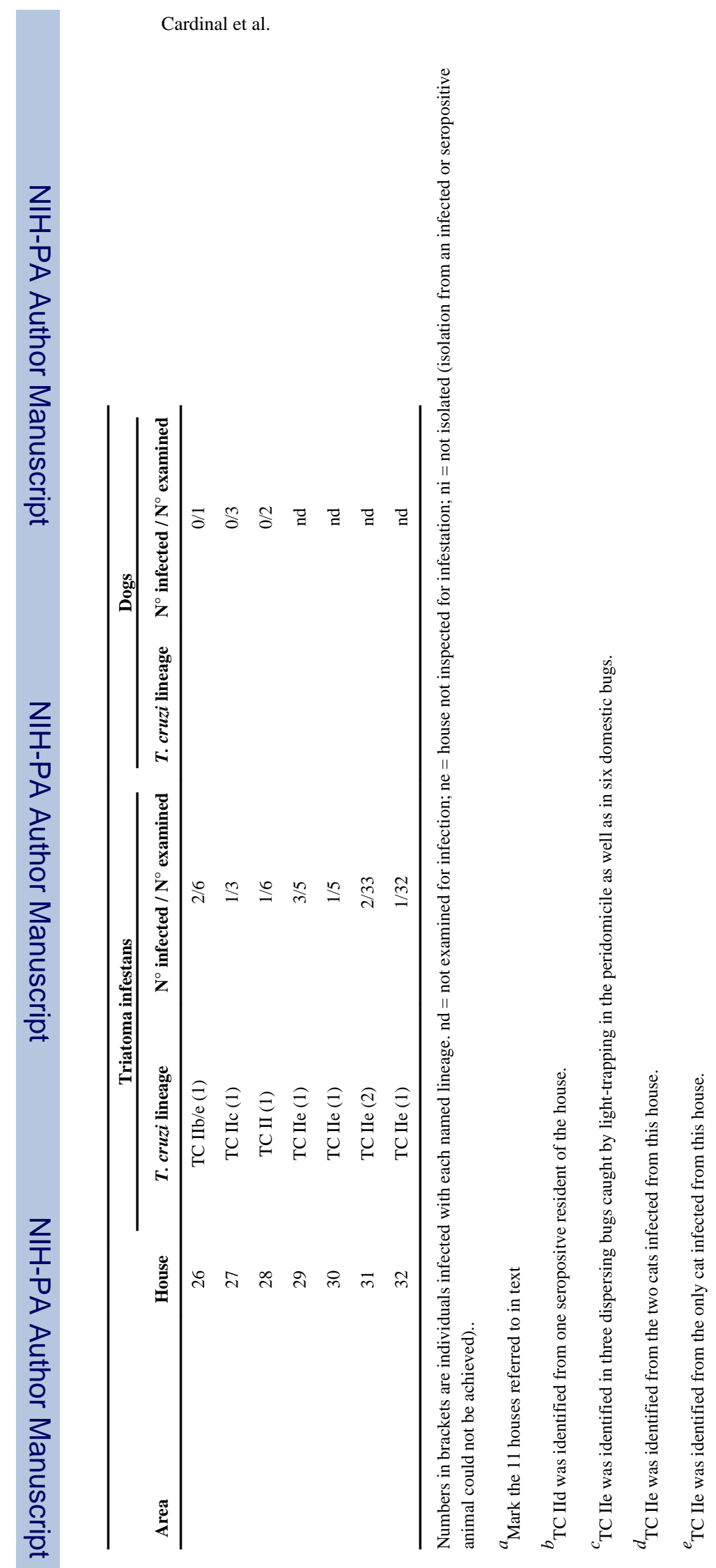

Int J Parasitol. Author manuscript; available in PMC 2011 July 26. 